\title{
A Developmental Theory of Instruction: Bridging Educational Priorities with De- velopmental Priorities
}

\section{Ajuste de las prioridades de desarrollo con las prioridades educativas: Princi- pios para una Teoría Eficiente de la Instrucción}

\author{
Andreas Panteli Demetriou \\ Department of Psychology, University of Cyprus (Cyprus) \\ ademetriouducy.ac.cy \\ ORCID: https://orcid.org/0000-0002-3773-4601
}

\begin{abstract}
This paper summarizes a theory of cognitive development and discusses its educational implications. The paper first outlines a set of principles that might allow tuning developmental priorities with educational priorities. It postulates, in contrast to several classic developmental theories, that developmental priorities change with development. It outlines the cognitive profile of four successive developmental cycles and presents evidence showing that developmental priorities change from interaction control in infancy to representational control in preschool to inferential control in primary school to logical truth control in adolescence. Studies are then summarized showing that the cognitive priorities of each cycle are the best predictors of school achievement in this or later cycles. Finally, we show that learning in different domains, such as language and mathematics, depends on an interaction between the general cognitive processes dominating in each cycle and the state of the symbol systems associated with this domain. If command of any of these systems is deficient, specific learning deficiencies may emerge, as in dyslexia and dyscalculia. Principles for learning to learn in general and for ameliorating these conditions are outlined.
\end{abstract}

Terms: Cognitive development; developmental priorities; learning difficulties; learning to learn.

\section{RESUMEN}

Este artículo resume una teoría del desarrollo cognitivo y examina sus implicaciones educativas. Primero, se define una serie de principios que permiten la coordinación de las prioridades evolutivas con las prioridades educativas. Se propone, contrariamente a varias teorías clásicas teorías del desarrollo, que las prioridades evolutivas cambian a través del desarrollo. Así, se describe el perfil cognitivo de cuatro ciclos sucesivos del desarrollo y se presenta evidencia mostrando que las prioridades evolutivas cambian desde el control interaccional en la infancia, al control representacional en la edad preescolar, al control inferencial en primaria, al control de la verdad lógica en la adolescencia. A continuación, se resumen varios estudios mostrando que las prioridades cognitivas de cada ciclo constituyen los mejores predictores del rendimiento escolar en aquel ciclo concreto o en ciclos subsiguientes. Finalmente, se muestra que el aprendizaje en varios dominios, como en lenguaje y las matemáticas, depende de la interacción entre los procesos cognitivos generales que dominan en cada ciclo y el estado de los sistemas simbólicos que están asociados con este dominio. Cuando el mando de cualquier de estos sistemas es deficiente, puede que deficiencias de aprendizaje específicas emerjan, como en dislexia y discalculia. Se discuten principios para aprender a aprender en general y para mejorar estas condiciones.

Palabras clave: desarrollo cognitivo; prioridades de desarrollo; dificultades de aprendizaje; aprendiendo a aprender. 


\section{Introduction}

This paper focuses on the relations between intellectual development and school learning. We propose a framework that may serve education in two important goals: support and enhance intellectual development through the years of school life and facilitate the attainment of the major learning goals for each school year across school subjects. Schools are challenging environments. Students learn many new skills and concepts over the years. School classrooms are complex environments: students in any classroom differ in ability, interests, and personality; teachers differ in education, teaching styles, and proficiency; different subjects, such as language or mathematics, differ conceptually and in their demands on understanding. It is admirable that most students do learn a lot at school. However, many students fall behind in learning at some points of their school life in at least some school subjects.

We advance a framework aiming to tune cognitive developmental priorities with educational priorities aiming to (i) satisfy cognitive developmental needs at successive phases in order to maximize the possibilities of each individual and (ii) capitalize on the possibilities emerging from developmental priorities. This framework is based on the following critical assumptions:

1. Learning and understanding are constrained by general-purpose mental processes underlying recognition, representation, processing, and integration of information and, also, self-regulation of action, problem solving, and learning. These processes strongly influence school learning (Demetriou et al., 2019a, 2019b; 2020; Gustafsson, 2008).

2. Learning and understanding are also constrained by the representational and procedural specificities of different domains of information, such as verbal, social, quantitative, and spatial information. General mental processes need to have facility with the representational units used in each domain, such as words, numbers, or images, to function efficiently (see Demetriou \& Spanoudis, 2018).

3. General processes change with development, because different mental processes dominate in successive developmental cycles depending upon the functional and adaptive needs of each phase. Overall, they shift from executive to inferential and self-awareness processes. The cognitive profile of successive age phases constrains what can be learned and how (Demetriou \& Spanoudis, 2018; Demetriou et al., 2017, 2018). Learning to learn changes, accordingly, acquiring more flexibility and scope.

4. Successive developmental profiles are associated with different learning difficulties, caused by a mismatch between the cognitive profile of each period and learning demands at school, such as difficulties in reading or mathematics.

The assumptions above suggest several important principles for an educationally useful cognitive developmental theory:

1. Educational priorities must capitalize on cognitive developmental priorities. Ignoring priorities may deprive learners from the support they need to consolidate mental processes to the level needed to move forward (Demetriou \& Spanoudis, 2018). Ignoring constraints may cause difficulties and delays in learning.

2. The theory must facilitate the domestication of general mechanisms and developmental priorities into specific domains of representation and learning which are important for education, such as language, mathematics, and science.

Below we substantiate each of these assumptions and discuss their implications for learning. This theory integrates validated assumptions from classic theories (Bruner, 1973; Piaget, 1970) and introduces some new assumptions emerging from recent research.

\section{Changing Developmental Priorities in Understanding the World}

There is an apparent paradox. On the one hand, Piagetian-like cognitive developmental stages do not exist. On the other hand, developing humans demonstrate drastically different cognitive profiles at different ages: infants are highly active and exploratory, but they are not symbolic; preschoolers are highly symbolic and imaginative, but they are not abstract; primary school children are organized and relational but they do not look for truth; adolescents are truth-oriented, looking for ideals (the best true states of the world) and their own identity (the best true state for themselves). Therefore, multiple levels of cognitive competence and skill coexist with broad cognitive profiles associated with different age periods. At successive phases, the mind is dominated by a different mixture of several general-purpose mental processes: (i) interaction control in infancy, (ii) attention and representation control in preschool, (iv) information integration and inferential control in primary school and (iv) truth control and self-determination in adolescence (Demetriou et al., 2018a, 2019b; Makris et al., 2017; Spanoudis et al., 2015). The precise combination of these processes dominating at successive phases will be outlined below. Overall, development aims to build an efficient representational mind able "to go beyond the information given" (Bruner, 1973): capitalize on experience to deal with the unexpected.

Research suggests four cycles differing in their dominant unit of representation, as follows: (1) interaction episodes and modality-specific memories; (2) language and mental images; (3) mental blueprints and action scripts defined by rules; (4) canonical principles prescribing acceptable possibilities. These cycles are time windows over which developmental priorities dominate until they are mastered; when mastered, they give way to the next priority. Thus, they are "regions of change" rather than hard boundaries;

\section{Episodic Thought}

It is beyond the concerns of this paper to embark on infant development. Discussion here is limited to highlighting the background in infancy which leads to the achievements of the following cycles. Interaction control is the major developmental task of the cycle of episodic thought: the infant must learn to interact with objects and persons, capitalizing on the affordances of the environment and his or her own bodily possibilities and skills (Thelen \& Spencer, 1998). Interaction with the environment generates episodic representations. These are proto-representations standing for interactive episodes such as fixating objects, searching for sound sources, grasping, eating, walking, etc.

Episodic representations are connected, especially in the second year. This occurs when (i) representations are sufficiently stable and (ii) the acoustic pattern of the respective words is sufficiently precise and stable in working memory so that they can be aligned. The fast acquisition of new words in this period 
(Carey, 2009) indicates that episodic representations are decontextualized from their context, becoming discrete representable units that may lexicalized by specific words. As a result, infants start scanning representations, search for specific elements in them, and align them; this is reflected in declarative sentences proliferating at this age. These processes involve some language awareness which reflects the phonological re-organization occurring at this phase (Farrar, Ashwell, \& Maag, 2005). This is the beginning of the next cycle.

\section{Realistic Representational Thought}

The refinement, interlinking, and lexicalization of episodic representations by the end of the second year make preschoolers highly symbolic: they are interested in symbols, they learn them fast, they massively use them in their interactions, and they have some awareness of their dual nature as real entities (e.g., a photograph or video) and representations of something else (e.g., the persons in the photograph or video) (DeLoache, 2000). This representational insight ("I can think of my parents", "I can think of my toys", "I can try my thoughts out") poses an important challenge to the toddler: representational control. That is, holding representations active and in focus so that information in the senses is encoded, processed, chosen or ignored, according to its relevance to the currently focused goal. Thus, control of attention is the major developmental priority of this cycle. This is an important developmental task because it allows more complex cognitive tasks, such as planning, learning to read and write, mathematics, etc. Attention control comprises several competences, such as choosing between stimuli to respond to, halt an activity, or shift between activities or stimuli, if required. Preschoolers respond well to these tasks by the age of 5-6 years (Zelazo, 2015).

Attention control involves awareness. For instance, to focus on this rather than another object requires one to be aware that one has eyes on a head which can be turned to objects at will. Toddlers are aware that perception and representations are connected: we know what we see, hear, touch, etc. This makes Theory of Mind (ToM) possible (Spanoudis et al., 2015). Children have a ToM when they understand that one's actions relate to one's own representations which derive from one's own perception (Demetriou et al., 2018a; Kazi et al., 2019).

Flexibility and abstraction are linked at this age: when children abstract a pattern from several stimuli are also flexible in switching across them. Representing and implementing an executive program is possible because it is based on the ability to abstract a common pattern across situations (e.g., all objects but one lie horizontally) and hold this pattern as a general representation that may guide action (Kharitonova \& Munacata, 2011). This ability allows mapping representational complexes onto each other and generalizing abstractions into more general rules, such as category tags (e.g., dogs bark), cardinal values in counting (e.g., "three" "five", etc.) and grasp their relations (five is more than three) (Carey, 2009; Siegler \& Braithwaite, 2017). Reasoning emerges in this as a metarepresentation of "A $\rightarrow B$ " relations. At this age, children draw the inference, but they cannot yet justify (see Kazi, Demetriou, Zhang, \& Yuan, 2012). Also, children at this age implement multi-step activities, as in dancing. This opens the way for the next cycle.

\section{Rule-based Thought}

With attentional control established, links between representations begin to emerge; language predication contributes to both their increasing differentiation and interlinking. This com- plexity presents a new developmental challenge: identify relations between representations and organize them so that they can be called upon in sake of understanding and interaction. Thus, inferential control is the major developmental priority in this cycle. The major task in this cycle is mastering the process dealing with relations between representations. Inductive and analogical inference is the major tool in rule induction and inter-linking (Gentner \& Hoyos, 2017). Solving these problems indicates that inference is fluid enough to access individual representations (e.g., numbers in an arithmetic task or figures in a Raven matrix) align them and identify relations between them (e.g., numbers double, figures increase by size) and bind them together according to underlying relations (e.g., size increase goes with decrease in color shade). Reasoning consolidates in this cycle as indicated by explicit deductive reasoning, where inferential relations go both ways: "if $A \rightarrow B$ ", then "not $B \rightarrow$ not $A$ " is also true. Also, eight-year-old children flexibly alternate between rules in sorting objects according to different properties (Zelazo, 2015).

The development of reasoning in this cycle comes with increasing awareness of the inferential processes themselves: awareness of underlying inferential processes (e.g., one may know something because one reasoned about it) and awareness of cognitive processes involved in different reasoning tasks (e.g., to find your way you need to imagine a road; to find a sum you need to combine the numbers) emerge at 8-10 years of age (Kazi et al., 2012, 2019; Spanoudis et al., 2015), indicating that inferential choices become the object of reflection in sake of optimizing conclusions. In turn, this generates awareness of inferential control: inference may take alternative roads depending on the representations connected and how they are connected. This awareness may be used to arrange representations according to the rule at hand, such as sequences of executive acts to formulate an action plan, extrapolate dimensions in inductive reasoning tasks according to the relations involved, or deduce conclusions from premises in deductive reasoning tasks (Kazi et al., 2019).

\section{Principle-based Thought}

Truth control is the developmental priority of principle-based thou$g h$. This requires the construction of principles underlying and constraining relations between rules. Therefore, control in this cycle is a logical metaprocess that defines constraints for acceptable and non-acceptable inferences. For instance, adolescents resist logical fallacies associated with the basic deductive schemes, modus ponens and modus tollens, already attained. They understand that $[\mathrm{A} \rightarrow \mathrm{B}$ ] does not imply necessarily $[\mathrm{B} \rightarrow \mathrm{A}]$ or [not $\mathrm{A} \rightarrow$ not $\mathrm{B}$ ] because $\mathrm{B}$ may occur for reasons other than $\mathrm{A}$. Grasping the fallacies is as close to a language of thought as reasoning can be. Truth control is also an epistemic metaprocess defining when statements or laws about reality are acceptable as valid descriptions. For instance, a statement about a relation may be (temporarily) accepted as true only when confounding variables were controlled according to acceptable practices of control; even then it is understood that some unknown variable may later falsify this relation. These representations are remote from actual objects and their properties. To be represented as such these representations often need ad hoc symbols, as in mathematics. Scientific terminology and related symbol systems stand for abstract relations or high-level multidimensional concepts, such as mass, energy, velocity, etc. This kind of representation may be a prerequisite to learn abstract scientific categories and their underlying principles.

Principle-based thought in adolescence is obvious in different domains. Adolescents grasp analogical relations within and 
across different hierarchies. Thus, control in this cycle is based on a suppositional-generative program enabling co-activation of conceptual spaces, evaluation against each other and formation of personal preferences and long-term life plans, such as choosing a course of studies. The suppositional stance brings disparate representational spaces under principles accepted as true so that values of truth and validity may vary according to the principle currently used. This achievement allows consistency in reasoning, because a single principle overwrites different contexts as it shifts processing from contextual information to their underlying relations.

When mastering principle-based thought, adolescents form accurate maps of mental functions and of their own strengths and weaknesses. As a result, they evaluate their own performance on cognitive tasks with increasing accuracy (Demetriou \& Efklides, 1989). For instance, they know where in school they are strong and where they are weak. Also, they cognize the constraints of different inferential processes; for instance, they recognize that it is easier to execute mental rotation than to calculate mathematical relations. Thus, they can make life-important choices, as when they choose a course of study or a profession based on an evaluation of their strengths and weaknesses.

\section{Convergence of Developmental and Educational Priorities}

Psychometrically research shows that a general factor, $\mathrm{g}$, ( $\mathrm{Ca}-$ rroll, 1998) always emerges despite differences between tasks used in different age periods (Demetriou \& Spanoudis, 2018). It is important to specify how changes across developmental cycles. We recently examined the composition of $\mathrm{g}$ from preschool to senility (Demetriou et al., 2017): $g$ in each cycle was marked by the processes associated above with the developmental priority of each cycle and cognizance of these processes. Specifically, the major marker of $g$ in realistic representations was attentional control and awareness of the perceptual origins of knowledge. In the rule-based cycle, $g$ was marked by advanced inductive reasoning, simple deductive reasoning, and awareness of inferential processes. In the principle-based cycle, g was marked by advanced deductive reasoning, mathematical reasoning, awareness of logical constraints of reasoning, and awareness of mental processes.

Cognizance drives re-integration of the processes dominating in a cycle into inclusive concepts or inferential schemes, catalyzing transition to the next cycle. As such, it is double-face processes: for the observer, it is abstraction and representation of patterns; for the thinker, it is awareness of mental states and processes. In early episodic thought, at 3-4 months of age, abstraction is based on dense perceptual properties, such as color or sound patterns, and it is basically modally specific. The next critical step comes in the second year when cross-modal information (e.g., look at this, it is read; a dog barking etc.,) may be integrated and lexicalized. Lexicalization facilitates shifting between properties and induction of unobservable properties in preschool. Learning of dimensional words, denoting dimensional values (e.g., "green" or "square") in this period facilitates the induction of abstract superordinate categories that eventually are represented by underlying rules at 6-7 years. This paves the way for the induction of abstract mathematical and scientific concepts (Sloutsky, 2010).

Mental functioning is unconscious most of the time. However, some aspects of mental functioning come in focus and become cognized, especially when things go wrong, or choices are to be made. Under these conditions, the object of real or mental action may become known and fed into reflection aiming to improve action or understanding. What is cognized at each cycle was specified above. Notably, there are differences between individuals in their sensitivity to ongoing mental processing, its objects, and the processes involved. These differences are part of differences in the rate of cognitive change and the production of new and better concepts and strategies. We showed longitudinally that a general factor of change driving development from realistic to rule based thought was dependent on individual differences in cognizance (Kazi et al., 2019).

\section{Causation in the Change of $g$}

We conducted several studies to examine if changing abstraction of relations and their cognizance would change intelligence. One study examined if building awareness of logical schemes and facility in transforming them into relevant mental models would catalyze transition from rule-based to principle-based reasoning (Christoforides et al., 2016). We trained 8- and 11-years old children, to become aware of the logical characteristics of the four basic logical schemes of conditional reasoning: modus ponens, modus tollens, affirming the consequent, and denying the antecedent; also we trained children to build mental models appropriate for each scheme and represent the relations involved. The aim was to examine if enhancing cognizance via conscious inferential activity about logical schemes would result into transition from rule-based to principle-based deductive reasoning. Additionally, children learned the notion of logical contradiction, how to adopt an analytical approach to logical arguments as contrasted to their "every-day" use in language, differentiate between the stated and the possibly implied meaning of propositions, recognize logical contradiction and truth in propositions and reality, and grasp the notions of logical necessity and sufficiency. Also, we investigated whether possible progress depends on attention control and working memory.

In terms of spontaneous developmental time, this training program pulled children up by an almost full developmental phase. That is, trained third graders handled problems at the level of principle-based reasoning if aided by context; sixth graders moved to this level regardless of content and context. Specifically, this intervention enabled both age groups to master the fallacies of affirming the consequent (knowing that when A occurs B also occurs does not allow any inference about A when knowing that B occurred) and denying the antecedent (under this condition, knowing that A did not occur does not allow any inference about B). Overall, awareness almost fully mediated the influence of training on deductive inference and improved significantly, depending on attention control and working memory. These findings show that when children think about reasoning they become aware of it; when they become aware of reasoning, they better handle other reasoning or cognitive tasks.

In another study we examined if training inductive reasoning in mathematics and related awareness would improve performance in several aspects of mathematics and generalize to other aspects of intelligence (Papageorgiou, Spanoudis, Christou, \& Demetriou, 2016). This study involved 10-11-years-old children. Children were instructed to identify the dimensions underlying the various mathematical reasoning tasks involving number series varying on several patterns (e.g., double, triple, half, one fourth) and mathematical analogies, explicitly conceive of their similarities and differences, group them according to organizational rules, and build the problem-solving skills associated with each. Thus, they were required to explicitly metarepresent both problem structures and processes as well as their associations. The emphasis was on formative concepts like "similarity", "dissimilarity or difference", "relations", and their instantiation 
in the various problem types. Children were also examined on various aspects of attention control, working memory, and reasoning (deductive, analogical, spatial, causal-scientific and mathematical).

The change in the domain of mathematical reasoning was considerable soon after the end of the intervention (effect size $=.38$ ), although it was not all of it sustainable about six months later (effect size $=.20$ ). However, the gains did transfer to domain-free analogical reasoning tasks and, to a lesser extent, to other domains, such as deductive reasoning. Gains in deductive reasoning were stable from second to third testing. Also, there was a strong effect on working memory and a less strong but significant effect on fluid reasoning and attention control. Obviously, these effects indicate that cognizance mediated the transfer of gains in relational thought to processes residing in the executive control level.

\section{Convergence in Developmental and Educational Priorities}

Cognitive ability is always a major predictor of school performance. Psychometric g (Jensen, 1998) accounts for the lion's share of school performance (about 30\%) (Demetriou et al., 2019a, 2019b; Gustafsson, 2008; Kaufman, Reynolds, Liu, Reynolds, McGrew, 2012). It is stressed, however, that the contribution of various mental processes to the prediction of school performance varies as a function of their relative importance in successive developmental cycles: the developmental priorities of each cycle are the best predictors of academic achievement in this or other cycles. Specifically, attention control, working memory, and perceptual awareness at 4-6 years, but not reasoning, are strong predictors of school performance in mathematics and language at 8-10 years (Demetriou, Kazali, \& Kazi, 2020). Working memory, cognitive flexibility in rule-shifting, and reasoning are the best predictors primary school grades. In secondary school, language, reasoning, and self-evaluation are the best predictors (Demetriou et al., 2019a). Also, in this age phase, a personality factor, conscientiousness is a significant predictor (Demetriou et al., 2019b).

\section{Learning and Development in Language and Mathematics}

General processes are not all that matters. We recognize that different domains present special demands for understanding and problem solving (Demetriou \& Spanoudis, 2018). Mastering different domains is a long process of building concepts and skills at successive levels of complexity through the interaction between the general processes dominating in each of the successive developmental cycles and the commensurate domain-specific processes of this cycle. With development, this interaction generates domain-specific concepts and skill, such as arithmetic operations in quantitative reasoning, syntax in language, sorting in categorization, etc. Thus, domains may diverge in developmental rate or highest level reached, if domain-specific processes diverge, because it is the interaction that matters in coping with developmental or learning tasks.

This is indicated by individual differences in mastering major developmental tasks at transitions between developmental cycles. All three major transitions are associated with fast learning of a new symbol system: speech at the transition between episodic and realistic representations; reading and writing at the transition between realistic representations and rule-based thought; highly specific idiosyncratic symbol systems at the transition between rule-based and principle-based thought. From an evolutionary point of view, the three systems are separated by thousands of years. Human language emerged about
200,000 years ago; reading and writing is about 5,000 years old; domain-specific symbol systems, such as mathematical notation as we know it, is only a few hundred years old. Mastering each system becomes increasingly difficult and learning difficulties increasingly likely; special education is increasingly needed to master each symbol systems. Children speak at about 2-3 years of age without any education. Most children learn to read and write at 6-7 years, but this is only possible if they are educated to do so. People command the symbolic systems of mathematics or different sciences in their fullness only after very long education.

In all three cases, however, difficulties arise when central and domain-specific processes are not well tuned to each other to allow coping with representational load needed to command the new symbol system. Speech delays relative to the typical speech of 2 years may occur either because children are limited in their capacity to handle language complexity during encoding ( $\underline{\mathrm{Pa}-}$ nagos et al., 1979) or because of specific phonological encoding problems (Paul \& Shriberg, 1982). Reading or arithmetic delays relative to the typical reading age of 6-7 years may occur because of attention control and representational awareness deficits or because of specific letter or quantity encoding difficulties. Below, we focus on two domains to highlight these principles, reading and mathematics from preschool to secondary school, because they are important throughout school life.

There is significant common ground between language and mathematics but also large differences. On the one hand, both domains are highly symbolic, requiring children to learn an arbitrary code where units may be specified at various levels and composed according to various, hierarchically organized, rules. Reading requires learning the script of one's language as a code for speech and the constraints of its composition, regardless of the specifics of a writing system. For instance, users of alphabetic writing systems have to learn that letters stand for sounds, composed into syllables standing for blocks of sounds, which form words which are the main units of meaning; these are composed into sentences according to grammatical and syntactic rules which signify and constrain meaning.

In a sense, mathematics is another special language, having its own script and syntactic and semantic rules. Number digits stand for number words and both stand for quantities. These are composed into larger numbers according to several rules: for instance, rules for the composition of whole numbers, fractions, and decimals. In turn, numbers may be combined and transformed according to other rules, such as arithmetic operations, algebraic relations, etc. Therefore, representation in both domains, regardless of the specifics of different language systems, is hierarchical from simple to complex; learning at school is organized, to a large extent, according to each system's hierarchical organization from simple to complex.

On the other hand, the two systems differ extensively in their representational functions, scope, specificity, and familiarity of use. Language is a universal omnipresent representational system and children are exposed to it since birth, if not earlier. Mathematics becomes part of everyday life much later, especially when formal schooling begins. Mathematics mostly draws on its own notational and representational systems which differ extensively from language. The rules and principles underlying transformation and composition of representations in the two systems are drastically different (e.g., grammar and syntax in language and arithmetic operations and algebraic rules in mathematics). Thus, from the point of view of education, it is interesting to specify similarities and differences of learning in these two domains during development. 
The present theory suggests that efficient learning in each domain would depend on tuning the demands of learning required by school in each subject with developmental priorities of the age concerned. Specific learning difficulties would emerge if $\mathrm{cu}$ rricular demands and children's possibilities diverge. We remind that attention control and perceptual awareness of the origins of representations and knowledge are the developmental priorities of the cycle of realistic representations, from 2 to 6 years. Learning of basic reading and arithmetic starts at preschool, at 5 to 6 years, and culminates in the first two primary school grades, at 6 to 8 years. Based on the principle of tuning developmental priorities with school priorities specified above, it is expected that delays in satisfying the two developmental priorities above would hinder learning the symbolic skills required for reading or arithmetic. Deficient attention control would disable children to accurately register and encode letters or numbers; deficient representational awareness would hinder them to understand that written words stand for the words of oral language or numerals stand for number words and related quantities. In the domain of language, about $20 \%$ of children in early primary school face strong difficulty in learning to read and write; a proportion of them, about $5-10 \%$ suffer from dyslexia, a serious condition interfering with every aspect of school life in children with normal intelligence. About the same number of children face difficulties in learning in mathematics. In a similar fashion, about $4-7 \%$ of children present developmental dyscalculia (Reigosa-Crespo et al., 2012).

It is important to examine how much reading and mathematics difficulties share common deficits in learning in the 2-6 years cycle and how much they depend with representational difficulties specific to each domain. Empirical evidence suggests a combination of common and specific deficits. Specifically, attention control and awareness are strong predictors of learning and performance in both reading and arithmetic: the state of inhibitory control, flexibility in shifting, and planning during preschool account for difficulties in reading and arithmetic (Clark, Pritchard, \& Woodward, 2010). Therefore, learning in both domains depends on the two major developmental priorities of this cycle. The ability to stay focused on symbols to register, recognize, and encode them for further processing are important at the very first stages of reading when mental representations are created to map the visual script seen. General representational awareness is needed as a top-down guide directing visual search and the integration of mental units into meaningful symbolic ensembles. In alphabetic languages, representational awareness takes the form of phonological awareness, because this is required to direct the composition of letters into units corresponding to words.

However, in serious learning difficulties in each domain, such as dyslexia or dyscalculia, weakness in attention control and representational awareness coexist with specific representational deficits in each domain. In reading, the phonological system does not have the resolution required for letter recognition and their composition in words. Dyslexic children face serious problems in phonological processing and encoding, which underlies the translation of letters into sounds and their integration into meaningful words. Thus, they cannot form sentences that would allow them to form a textbase representation capturing the integral meaning of the text in front of them (Kintsch \& Rawson, 2007; Siegel, 2006). Likewise, in dyscalculic children, the numerocity coding system is not precise enough to allow building representations for different quantities. It seems that dyscalculia is caused by a deficit in numerocity coding (Butterworth, 2010). Numerocity coding is mapping symbols onto representations of quantities: exactly representation one as a quantity of one, two as a quantity of two, three as a quantity of three, etc. Children with a deficient numerocity coding system "have a poor intuitive sense of quantity, ... poor understanding of more and less, and slow learning of Arabic numerals, number words, and their meanings" (van Marle et al., 2013, p.9). Thus, they have difficulty in enumerating small sets of up to 9 elements, compare small magnitudes, such as 5 to 7 and 7 to 5 and do simple mental arithmetic by adding or subtracting numbers between 1 and 9 .

A deficit in coding numerocity as precise magnitudes makes learning to count difficult because counting words lack the exact corresponding representations to be associated with. In turn, this hinders the functioning of two primary constructs of mathematical reasoning. The Approximate Number System (ANS) and the Mental Number Line (MNL) (Dehaene, 2011). The ANS is the background for the development and learning of mathematics in the fashion that natural language is the background for the development of reading and writing. The core of the ANS is subitization, i.e., automatic perception of numerocity of up to 3-4 elements. Subitization is present in infancy (and other animals as well); infants also recognize the basics of arithmetic operations, such as the addition or subtraction of elements within the subitization limit. This ability develops into the MNL in early childhood, which is the pivot of the ANS. Numbers on the MNL are ordered from left to right according to magnitude. The MNL allows approximate comparisons between numbers; the accuracy of these comparisons decreases with increasing number magnitude or decreasing distance between numbers. For instance, it is easier to judge that 27 is larger than 23 than to judge if 727 is larger than 723. Deficits in these systems hinder the learning of rules underlying the relations between quantities. There is evidence that numbers on the number line overlap in dyscalculic children, causing difficulties in number comparisons (Mussolin et al., 2010).

Specific problems in one of the two domains is not necessarily associated with similar problems in the other domain. Children with dyscalculia face problems in associating Arabic numerals with their representations of magnitudes but they do not have problems in associating letters with phonemes; dyslexics faced problems with letter and digit recognition and naming but no problem with magnitude processing, symbolic or mon-symbolic (Rubinstein \& Henik, 2006).

\section{Conclusions: Where is Learning to Learn?}

We summarized a theory cognitive development aiming to unify cognitive developmental, psychometric, and clinical theories of intellectual development and learning. This theory postulates that cognitive development occurs via several cycles of representational expansion and reorganization which allow increasingly accurate multidimensional representation of the world. Each new form of representation poses a new problem of mental control: attention at preschool, inferential in childhood, and logical control in adolescence. In other words, mental control gradually shifts from perceptual and action systems to inferential and logical systems. Mental awareness is an important component of this process, reflecting the cognitive processes coming under control in each cycle.

Control is multiply exercised according to the symbol systems used; symbol systems stand for different levels of mental complexity and express variably the same aspects of reality or different levels of complexity of reality. For instance, oral language, written language, mathematics, etc. Commanding a system requires facility with the symbol systems involved; for instan- 
ce, acoustic patterns standing for spoken words, visual patterns standing for written words, visual patterns standing for quantities, etc. If grasping the external patterns and representing them is deficient, their learning and use would be also deficient, as in speech delays at the transition from infancy to early preschool or reading and arithmetic difficulties at the transition from preschool to secondary school.

Learning to learn in sake of taking control of one's own development implies accurate self-monitoring and understanding at two levels: Awareness of mental processes as such and awareness of one's own strengths and limitations in each process. This varies systematically with development. Infants have minimal self-awareness and self-understanding. Thus, learning to learn is by definition very limited. However, experiences may be systematically organized to enable the infant to discover possibilities and limitations in interactions with different kinds or assemblies of objects. For instance, objects can be arranged variably within the subitization limit, so that they can be counted, numbered, and tagged visually so that representations about number can be constructed. At the edge between infancy and toddlerhood, with the emergence of language, education must enable the infant to connect basic processes with representations and elaborate them into the domain-specific processes, such as numbering and categorization.

In preschool, instruction must focus on managing perceptual systems and action in reference to varying goals; explicit use of different means to symbolize concepts and actions by means, such as language, photographs, drawings, and noting their advantages and disadvantages would be important for mastering mental representation. Children must be instructed to explore how the appearance of objects may change without affecting their identity (e.g., transformers teach that variation of appearances is does not alter object identity). They must be led to alternate between one's own point of view and another's point of view by systematically exchanging and comparing positions, to realize that different perspectives may create different representations and different beliefs in different persons. Also, associating alternative representations with the same reality (e.g., number digits and number words) may be helpful in enabling the child to dissociate representation from thought as such.

To advance rule-based thought, instruction should focus on underlying relations connecting representations. Relational thought must be explicitly trained to recognize constraints of different types of relations as in mathematics. In early primary school years children start to become aware of mental activity and of the differences between cognitive functions. Thus, education must build awareness of the differences between mental functions and of their differential impact on learning. For instance, children must realize that recall of information from memory and its connection with what is in front of their eyes facilitates understanding of new information. In turn, they must learn that rehearsal facilitates storage of new information in long-term memory for later use and that this may be tested by asking questions to themselves. In adolescence, education must elaborate on the logical forms and constraints of principle-based thought in identifying truth and validity. Also, self-awareness becomes process-driven and self-concept differentiates. Thus, education must focus on awareness of the differences between mental processes in different cognitive domains and elaborate on processes of self-monitoring and self-evaluation that would refine self-concepts about strengths and weakness. There is research showing that a major problem of learning in adolescence is lenient self-representations protracting narcissistic self-beliefs based on social desirability rather than actual performance.
In developmental difficulties, remedial programs must include training in the symbol systems affected and in how the general processes may be used on them. Children must be trained to command the phonology of their language in speech delays, the visual-phonological structure of a written system, and the representation of different amounts and the relations between their transformations. This must also involve the inferential mechanisms needed to integrate sound patterns and production or written symbols and sentence production into semantically meaningful structures. Children must be trained to recognize when they have difficulties in assembling elements into higher units in language or arithmetic and realize that effort and focusing on specific aspects of these representations may generate the elements needed in problem solving in each domain.

\section{References}

Bruner, J. (1973). Beyond the information given: Studies in the psychology of knowing. New York. Norton.

Butterworth, B. (2010). Foundational numerical capacities and the origins of dyscalculia. Trends in Cognitive Sciences, 14, 534-541. doi:10.1016/j.tics.2010.09.007

Carey, S. (2009). The Origin of Concepts. New York: Oxford University Press.

Carroll, I. B. (1993). Human cognitive abilities: A survey of factor-analytic studies; New York: Cambridge University Press.

Christoforides, M., Spanoudis, G., Demetriou, A. (2016). Coping with logical fallacies: A developmental training program for learning to reason. Child Development, 87, 1856-1876.

Clark, C. A., Pritchard, V. E., \& Woodward, L. J. (2010). Preschool executive functioning abilities predict early mathematics achievement. Developmental Psychology, 46, 1176-1191.

Dehaene, S. (2011). The number sense ( $2^{\text {nd }}$ ed.). New York: Oxford University Press.

DeLoache, I. S. (2000). Dual representation and young children's use of scale models. Child Development, 71, 329-338. doi:10.1111/1467-8624.00148

Demetriou A, \& Efklides, A. (1989). The person's conception of the structures of developing 16 intellect: Early adolescence to middle age. Genetic, Social, and General Psychology Monographs, 115, 371-423.

Demetriou, A., Kazali, E., \& Kazi, S. (2020). Predicting school performance from preschool to primary school. Cognitive Development,

Demetriou, A., Kazi, S., Spanoudis, G., \& Makris, N. (2019a). Predicting school performance from cognitive ability, self-representation, and personality from primary school to senior high school. Intelligence 76, https://doi.org/10.1016/j.inte11.2019.101381

Demetriou, A., Kazi, S., Spanoudis, G., Makris, N. (2020). Cognitive ability, cognitive self-awareness, and school performance: From childhood to adolescence. Intelligence, in press.

Demetriou, A., Kazi, S., Spanoudis, G., Makris, N. (2019b). Predicting school performance from cognitive ability, self-representation, and personality from primary school to senior high school. Intelligence, doi.org/10.1016/j.intell.2019.101381.

Demetriou, A., Makris, N., Kazi, S., Spanoudis, G., \& Shayer, M. (2018a). The developmental trinity of mind: Cognizance, executive control, and reasoning. WIREs Cognitive Science, 2018;e1461. https://doi.org/10.1002/wcs.1461

Demetriou, A., Makris, N., Tachmatzidis, D., Kazi, S., \& Spanoudis, G. (2019a). Decomposing the influence of mental processes on academic performance. Intelligence, 77, doi.org/10.1016/j.intell.2019.101404. 
Demetriou, A., \& Spanoudis, G. (2018). Growing minds: A general theory of intelligence and learning. London: Routledge.

Demetriou, A., Makris, N., Kazi, S., Spanoudis, G., Shayer, M., \& Kazali, E. (2018b). Mapping the dimensions of general intelligence: An integrated differential-developmental theory. Human Development, 61, 4-42. http://dx.doi.or$g / 10.1159 \% 2 F 000484450$.

Demetriou, A., Spanoudis, G., Kazi, S., Mouyi, A., Žebec., M. S., Kazali, E., Golino, H. F., Bakracevic, K., \& Shayer (2017). Developmental differentiation and binding of mental processes with re-morphing $g$ through the life-span. Journal of Intelligence, 5, 23; doi:10.3390/jintelligence5020023.

Farrar, M. I., Ashwell, S., \& Maag, L. (2005). The emergence of phonological awareness: Connections to language and theory of mind development. First Language, 25, 157-172, DOI: $10.1177 / 0142723705051980$

Gentner, D., \& Hoyos, C. (2017). Analogy and abstraction. Topics in Cognitive Science, 9, 672-693, DOI: 10.1111/tops.12278.

Gustafsson, I. E. (2008). Schooling and intelligence: Effects of track of study on level and profile of cognitive abilities. In P. C. Kyllonen, R. D. Roberts, \& L. Stankov (Eds.), Extending intelligence: Enhancement and new constructs (pp. 37-59). New York: Lawrence Erlbaum Associates.

Jensen, A. R. (1998). The g factor: The science of mental ability. Westport, CT: Praeger.

Kazi, S., Demetriou, A., Spanoudis, G., Zhang, X.K., \& Wang, Y. (2012). Mind-culture interactions: How writing molds mental fluidity. Intelligence, 40, 622-637.

Kazi, S., Kazali, E., Makris, N., Spanoudis, G., \& Demetriou, A. (2019). Cognizance in cognitive development: A longitudinal study. Cognitive Development, 52, https://doi.org/10.1016/j. cogdev.2019.100805

Kaufman, S. B., Reynolds, M. R., Liu, X., Kaufman, A. S., \& McGrew, K. S. (2012). Are cognitive g and academic achievement $\mathrm{g}$ one and the same $\mathrm{g}$ ? An exploration on the Woodcock-Johnson and Kaufman tests. Intelligence, 40, 123-138.

Kharitonova, M., \& Munacata, Y. (2011). The role of representations in executive function: investigating a developmental link between flexibility and abstraction. Frontiers in Psycho$\log y$.

Kintsch, W., \& Rawson, K. A. (2007). Comprehension. In M. J. Snowling, \& Hulme, C. (Eds.), The science of reading: A handbook (pp. 209-226). Oxford: Blackwell.

Makris, N., Tahmatzidis, D., Demetriou, A., \& Spanoudis, G. (2017). Mapping the evolving core of intelligence: Relations between executive control, reasoning, language, and awareness. Intelligence, 62, 12-30.
Mussolin, C., Mejias, S., \& Noël, M. P. (2010). Symbolic and nonsymbolic number comparison in children with and without dyscalculia. Cognition 115, 10-25.

Panagos, I., Quine, M., \& Klich, R. (1979). Syntactic and phonological influences on children's articulation. Journal of Speech and Hearing Research, 22, 841-848.

Papageorgiou, E., Christou, C., Spanoudis, G., \& Demetriou, A. (2016). Augmenting intelligence: Developmental limits to learning-based cognitive change. Intelligence, 56, 16-27.

Paul, R., \& Shriberg, L. D. (1982). Associations between phonology and syntax in speech-delayed children. Journal of Speech, Language, and Hearing Research, 25, 536-547.

Piaget, I. (1970). Piaget's theory. In P. H. Mussen (Ed.), Carmichael's handbook of child development (pp. 703-732). New York, NY: Wiley.

Reigosa-Crespo, V., Valdes-Sosa, M., Butterworth, B., Estevez, $\underline{\text { R., Rodríguez, M., Santos, E., Torres, P., Suarez, R., \& Lage, }}$ A. (2012). Basic Numerical Capacities and Prevalence of Developmental Dyscalculia: The Havana Survey. Developmental Psychology, 48, 123-135, DOI: 10.1037/a0025356

Rubinstein, O., \& Henik, A. (2006). Double dissociation of functions in developmental dyslexia and dyscalculia. Journal of Educational Psychology, 98, 854-867.

Siegler, R. S., \& Braithwaite, D. W. (2017). Numerical development. Annual Review of Psychology, 68: 12.1-12.27, 10.1146/annurev-psych-010416-044101

Sloutsky, V. M. (2010). From perceptual categories to concepts: What develops? Cognitive Science, 34, 1244-1286.

Spanoudis, G., Demetriou, A., Kazi, S., Giorgala, K., \& Zenonos, V. (2015). Embedding cognizance in intellectual development. Journal of Experimental Child Psychology, 132, 32-50.

Thelen, E. \& Spencer, J. P. (1998). Postural control during reaching in young infants: A dynamic systems approach. Neuroscience and Biobehavioral Review, 22, 4, 507-514, DOI:10.1016/ $\underline{\text { S0149-7634(97)00037-7 }}$

Van Marle, K., Chu, F. W., \& Geary, D. C. (2013). Acuity of the approximate number system and preschoolers' quantitative development, Developmental Science, 17, 492-505, doi. org /10.1111/desc. 12143

Zelazo, P. D. (2015). Executive function: Reflection, iterative reprocessing, complexity, and the developing brain. Developmental Review, 38, 55-68. 